\title{
Similarities and Differences between Public and Private Sector Leadership Strategies in the Caribbean: Empirical Findings on the Link between Leadership, Culture, and Performance
}

\author{
Paul L. Flemming \\ Correspondence: Paul L. Flemming, School Of Business, University of the Virgin Islands, USA.
}

Received: September 7, 2016

Accepted: September 22, 2016 Online Published: September 29, 2016

doi:10.11114/bms.v2i4.1863

URL: http://dx.doi.org/10.11114/bms.v2i4.1863

\begin{abstract}
Conventional theory, which holds that there is a significant difference between leadership in the public and private sectors as leaders manage organizational culture to achieve strategic performance, has begun to be disputed by recent scholars in organizational behavior. The purpose of this study was to validate the views of organizational practitioners that private sector leaders are best suited to facilitate organizational efficiency by examining the link between leaders, culture, and employee performance. The Multifactor Leadership Questionnaire (MLQ) was distributed to middle managers (N=200) who worked in public and private sector organizations across the United States Virgin Islands to examine how the leaders used organizational culture to improve their organizations' performances. The study found that leadership practices in both sectors have significant effects on performance. While the hierarchy culture was dominant in government agencies dictating effectiveness is the adherence to strict rules and regulations, the criteria of effectiveness most prominent in the private sector was market culture evident in the achieving of goals, outpacing the competition, increasing market share, and acquiring premium levels of financial returns. These findings suggest that, contrary to conventional theory, those leaders with the greatest organizational success are not restricted only to the private sector; but they are also evident in the public sector. This study concluded that leadership in both the public and the private sectors can induce a significant level of performance when strategies are aligned with organization's culture and objectives as these organizations developed, grow, and mature.
\end{abstract}

Keywords: leadership, performance, organizational culture

\section{Introduction}

There seems to be a disconnect in research regarding the relationship between leadership in the public and private sector. This study seeks to examine the link among public and private sector leaders as a mediator of culture and performance. There are many types of leaders each having a specific sets of characteristics that become evident in performing their functions of leadership (Parry, 1999). Although leadership is conceptualized as a process to achieve a specific result, the components common to nearly all of the classifications, and one that will be applied to define leadership behavior in this study, is that leadership is an influential process that assists groups of individuals toward goal attainment within an organization's environments (Northouse, 2004). Bass (1999) argued that leadership is a multifaceted issue. He asserted that there are business leaders, political leaders, and community leaders. Leadership can be viewed as a process of social change; a process of persuasion by which an individual or team induces a group to pursue objectives held by the leader or shared by the leader and his or her followers (Gardner, 1990; Higgs, 2003). This study embodies the definitions articulated by Parry (1999); Northouse (2004); and Gardner (1990; Higgs, 2003) thus view leadership in the context of public and private sector organizations. This study considers leadership as one who represent formal authority in private, public and nonprofit organizations to provide appropriate customer service to the degree that the results are sustainable performed.

\section{Literature Review}

\subsection{Study of Public and Private Sector}

One of the similarities that are common to the public and private sector is political management. Public and private leaders are both concerned with meeting their staffing needs, motivating subordinates, and obtaining financing to maintain efficient operations. Both sectors' leadership must address issues internal and external to their organizations. There are operational agreements to be reached and maintained; elements of persuasion and coercion to be weighted; and 
gains and losses to be realized. For example, Starling, (1993) noted that the president of the Ford Motor company and the commissioner of health and human services have to be concerned with many of these same leadership issues, which must be carefully planned for and acted upon to promote the organization's interest (Gordon \& Milakovich, 1998). Similarly, it behooves leaders in both sectors to analyze and interpret political, social, and economic trends; to evaluate the consequences of legislative actions; and to possess the required competency to persuade and bargain effectively, thereby furthering their organization's objective. In addition to being politically savvy, leaders in both the public and the private sectors must also be competent in implementing shareholders' and stakeholders' established goals and objectives. According to Gordon and Milakovich (1998) and Starling (1993), a program is a major organizational endeavor with objectives. They further asserted that in government organizations, programs are usually designed to fulfill statutory requirements through effective implementation and evaluation. Consistent with the preceding argument, Guth, (1980) argued that programs in both public and private sectors require a comprehensive understanding of five traditional management functions: planning, decision making, organizing, leading and controlling. Farkas and Wetlaufer (1996) postulated the idea that business institutions have grown, expanded and changed over the past twenty-five years and leaders must think globally in establishing long-term strategic programs. Magretta (1998) articulated the need for leaders to have a vested interest in running programs and other activities that are properly designed, strategically directed to meet their intended goals, efficient in expenditures of organizational resources, and effective in their outcome (Gordon \& Milakovich, 1998; MahgoubAli, 2004; Starling, 1993). Mumford, Zaccaro, Harding, Jacobs, and Fleishman (2000) further argued that leaders must be able to communicate vision, establish goals, monitor progress, and motivate subordinates as they attempt to implement a given solution plan. Additionally, Mumford et al. (2000) pointed out that if a leader manages to ensure that all functions critical to a given task accomplishment and group maintenance are adequately addressed, then the leader has done his or her job well.

Starling (1993) argued that there are three kinds of resources that are essential to the accomplishment of an organization's mission: people, money and information. For instance, about four fifths of a police department's budget goes to salaries. On the other hand, Dell Corporation workforce is made up of approximately 82,000 executive team members who live and work in six continents Felfe, \& Schyns, (2004). While it could be argued that the right plans, structures and procedures are critical phenomenon in the lifecycle of an organization, the capabilities that lead to program success come from people' skill, discipline, motivation and intelligence (Gordon \& Milakovich, 1998; Starling, 1993). Thus, leading and developing followers is the heart of successful, high-performance organizations. Additionally, the adequate supply of money forms the sinews of public and private sectors' business operation. While monies are collected in the form of taxes in the public sector, the private sector focuses its revenue resources from the sale of goods and services (Farkas \& Wetlaufer, 1996; Gordon \& Milakovich, 1998; MahgoubAli, 2004; Starling, 1993).

While Starling (1993) and Gordon and Milakovich (1998) concurred that there are similarities in public and private sector leaderships, they argued that there are also significant differences between both sectors. These differences can be traced to structure, incentives, settings, and purposes. The first fundamental difference lies within the structure. It was clearly articulated by Starling (1993) that the leadership responsibility is blurred in the public sector. In other words, government does not give full authority to any one leader or institution. Thus, as a consequence of this blurred delineation of authority, agency heads, unlike their counterparts in the private sector, cannot set their budget levels. Rather, there is a process of checks and balances which involves department heads, the office of management and budget, the executive branch, and the legislature. Public sector leaders must often operate in structures designed by other groups, to include both boards and commissions drawn from the private industry; work with individuals whose assignments are often outside the scope of the leader's control; and accomplish their goals in less time than allowed for by their counterpart in the private sector. Additionally, unlike many private leaders, public leaders must operate under the watchful eyes of the general public, scrutinize and criticize by the press, and other government agencies. Finally, any planning that public organizations engage in must be shared and approved by the legislative body, the executive branch and other governing boards (Farkas, \& Wetlaufer, 1996; Gordon \& Milakovich, 1998). The second significant difference is in the incentives approach. Gordon and Milakovich (1998) argued that in contrast to the narrowly defined, profit-oriented concerns shared by executive leaders in the private sector, there are often conflicting incentives established by leaders in the public sector. If there are disharmonious relationships among leaders in different agencies over a policy approach, the organizations will not function with the same smoothness if the incentives were agreed upon. Additionally, most leaders in public organizations succumb to diffuse responsibility due to a lack of accountability for decision making. Although separation of powers can be associated with this leadership dilemma, a fragmented executive branch is a major contributor to the plight of public leadership. While it was argued that centralized executive authority is paramount for decision making in the private industry, the public organizational leaders must confer with citizen groups, courts, and various types of board and commissions. Thus, there is no clear chain of command as it relates to leadership direction due to the fact that there are numerous outside influences from stakeholders that exert pressure to influence the power hierarchies in government agencies and departments (Farkas \& Wetlaufer, 1996; Gordon \& Milakovich, 1998; Starling, 1993). Third, there are not 
only differences in structures and incentives, but differences are also evident in public and private sector organizational settings (Farkas \& Wetlaufer, 1996). Leadership in the public sector is severely scrutinized by stakeholders, to include the media and interest groups, who feel that they have a right to know about every decision a leader makes in his / her organization as result of the Freedom of Information Act. Further, it is no surprise that Starling (1993) noted that there is a general consensus among business professionals that government is ruled by leakage, and that employees use the media and the political networks to accomplish their goals instead of discussing the issues with their leaders. It must be also noted that one significant leadership challenge encountered by public sector leaders is tenure. Most Caribbean nations operate within a democratic political system in which the leadership team is subject to change every four or five years. In contrast, private sector leaders tend to stay with the firm longer and thereby providing continuity (Farkas \& Wetlaufer, 1996; Gordon \& Milakovich, 1998; Starling, 1993).

As it relates to purposes, both public and private organizations use resources to produce goods and services. Mahgoubali, (2004) asserted that whereas in the private sector products and services are provided to customers based on their demand for monetary payment, the goal of public sector leaders is to operate programs in the form of services to a wider constituent support primarily by tax revenues. However, this trend is now changing and government-operated organizations are now charging fees for certain category of services provided. For example, Gordon and Milakovich (1998) pointed out that the use of hospital services now requires payments upon completion of the procedures; and fees are also charged by government agencies for the use of airports and seaports. Another key difference is that private organizations have the leverage to define their own markets and set their own strategic goals; but leaders in public organizations are mandated to establish policies in pursuit of goals set for them by their legislatures. It is evident that public managers and leaders have limited freedom to alter basic organizational goals, while private leaders can use internal indicators to evaluate organizational performance, oftentimes focusing on the profit and loss margins, public leaders are subjected to criticisms from stakeholders such as the general public, the legislature, the executive branch, and the courts, and it is those stakeholders that have the last word in assessing public sector leaders' responsibilities (Farkas \& Wetlaufer, 1996). The purpose of this study is not only to examine the similarities and differences exist in public and private organizations, but also to investigate the relationship between the cultural, performance and leadership traits that contribute to organizational effectiveness. Based on the research framework and the three components of the under investigation, the study proposed three specific questions: What are the impact of the relationship between leadership traits and culture types on organizational performance? How can the practice of the four culture types and there interaction with the four leadership traits contribute to organizational effectiveness; and how can these relationships, if any exist, contribute to the understanding organizational productivity and efficiency by decisions makers. By answering these questions and finding the gaps, the study suggests a more synergistic methodology to resolve organizational dysfunctionality.

\subsection{Organizational Leadership and Performance}

Transformational leadership theory was first introduced by Burns (1978) who was analyzing political leadership in public sector organizations (Barbuto, 2005; Llies, Judge \& Wagner, 2006). The theory suggests that some leaders, through their personal traits and their relationships with followers, go beyond a simple exchange of resources and productivity but seek to develop and empower individuals to their fullest potential (Nahavandi, 2006). Transformational leadership is a process that changes and transforms followers. It focuses on individual's emotions, values, ethics, standards, and long-term goals (Avolio, Bass \& Jung, 1999); and it assesses the motives of followers with an aim of satisfying their needs, and in treating them with dignity and respect (Banerji \& Krishnan, 2000; Barbuto, 2005; Bass, 1999). From the views of scholars and practitioners, transformational leadership has the elements of a wider range of applicability. The leadership theory can be employed to influence followers on an individual and group level, and it can also be instrumental in influencing an entire organization and its culture (Burns, 1978). Carless (1998) further asserted that while the styles of laissez-faire and transactional leadership, which are based on passive and active aspects of the leader and his environments, the transformational leadership, which is based on personal relationships, intellectual challenge, inspirational motivation and behavioral charisma are also seen as effective traits in enhancing organizational outcomes. Yuki (2002) also stated that the traits of transformational leadership were considered the leadership of choice as it relates to facilitating organizational performance.

It was further argued that leadership is not limited to executives at higher levels within organizations. Hersey and Blanchard (1998) argued that leaders at all levels of the organization should have the diagnostic ability and adaptability if they are to be successful in leading across diverse situations. An important contribution to the theory of leadership came from Burns (1978) and Bass (1985) when a comprehensive analysis was made from the research findings into the behaviors of political leadership. Their research showed that political leadership can be defined as transactional or transformational. Additionally, Bass (1994) argued that transformational leaders act as role models for their followers, motivate and inspire followers through team efforts, challenge and stimulate their followers intellectually, and facilitate 
personal development and growth in their followers. Schimmoeller (2006) articulated that transformational leaders may be more effective in aligning organizations' philosophical objectives with their expected performances, when compared to transactional leaders whose influences are impacted by contract terms with their followers. According to Bass (1999), transformational leadership refers to the ability of the leader to move followers beyond their "self-interest through idealized influence (charisma), inspiration, intellectual stimulation, or individualized consideration" (p.11). Transformational leaders seek to elevate their followers' immediate needs and concerns transforming both the follower and leaders to a higher level of self-actualization.

According to Bass (1985), the link between leadership and performance has created scholarly debates with practitioners and scholars alike. Although it can be argued that research on the relationship between different leadership styles and organizational performance have yielded negative results, Bass (1985) found a high correlation between transformational traits and the organizational productivity specifically relating to performance. Bass (1985) also found that this association with the leadership performance phenomenon was more impressive than the positive relationship between the leader's transactional style and the organizational effectiveness. Other literature on the theory of leadership pointed out negative correlation between the transactional leadership style and organizational performance (Parry, 2003). Bass (1985) argued, on the other hand, that employees exert more interest and take initiative to perform their duties if they support the appointment of the leader or have stake in the organization in which they work. This synergy of employee and leader interaction contributes to the increase productivity and level of performance which employees are measured. According to Casimir (2006) and Parry (2003), they asserted that resent studies in leadership styles in public sector organizations found that leaders that demonstrated transformational leadership traits have positive effects on the innovation of their employees and their organizations, overall performances.

\subsection{Organizational Leadership and Culture}

The relationship between leadership and culture is another construct that need to be examined in order to determine the relation that exist between organizational culture types and leadership styles in organizational effectiveness. Shrader, Taylor \& Dalton (1984) argued that a growing body of literature has verified that the determinant of organizational performance is a contingent relation between a firm's strategy, culture and its environments. DeTienne, Dyer, Hoopes, and Harris (2004) also asserted that an effective corporate culture consists of norms and practices that provides the free flow of information among employees and across department lines. Cameron and Quinn (2006) crystallized the concept of effectiveness to the culture types by arguing that the criteria of effectiveness most prominent in a hierarchy culture are efficiency, timeliness, smooth functioning, and predictability. They asserted that the dominant operational theory that drives organizational success is control, which foster efficiency and effectiveness. However, in hierarchy organizations, such as government agencies, the dominant operational theory that dictates effectiveness is the adherence to strict rules and regulations. While the underlying premise of hierarchy organizations emphasizes the importance of policies and guidelines, the criteria of effectiveness most prominent in a market culture are achieving goals, outpacing the competition, increasing market share, and acquiring premium levels of financial returns. Further the dominant operational theory that galvanized organizational success is competition which creates an impetus for higher levels of productivity and therefore higher levels of effectiveness. The inability to increase market share, enhance revenues, and achieve productivity was seen as failure (Cameron \& Quinn, 2006). On the contrary, in the clan culture, the criteria of effectiveness most highly valued include cohesion, high levels of employee morale and satisfaction, human resource development, and teamwork. The operational theory that dominates this culture type is involvement and participation of employees that fosters empowerment and commitment. The literature also found that committed, satisfied employees produce more efficient and effective service (Cameron \& Quinn, 2006; Hooijberg \& Petrock, 1993). Finally, Hooijberg and Petrock (1993) asserted that the adhocracy organizational culture emphasized the importance of new products, creative solutions to problems, cutting-edge technologies, and strategic growth in new market niches as the dominant effective criteria. However, the underlying operational phenomenon is innovation and new ideas, which create new markets, increase customers and new opportunities (Cameron \& Quinn, 2006).

\subsection{Organizational Culture and Performance}

Howard (1998) argued that the concept of organizational culture has evoked serious research into the behavioral sciences of organizations' performances, and scientists from the field of anthropology and sociology have been studying the impact of culture on organizational effectiveness for many years. However, the arguments postulated by Schein (1992) asserted that organizational culture is an abstract and complex phenomenon, thus many definitions of culture exist and that the concept of organizations is ambiguous. As a result, scholars in organizational behavior (O'Reilly, 1989; Reynolds, 1986; Rowden, 2002) presented two schools of thought conceptualizing the meaning of organizational culture. One school defined organizational culture as observable traits focusing on the physical characteristics of the organization such as architecture, artwork, dress patterns, language, stories, myths, behavior, formal rules, rituals, ceremonies, and appearances. The other school argued that the physical characteristics are not culture types; rather they are the symbolic 
constructs of the unobservable characteristics of culture such as the norms, beliefs, assumptions, ideologies, values and shared perceptions held by members of the organizations (Hendrick 2003; Nahavandi, 2006; Robbins, 2002; Yukl, 2002). However, Schein (1990) argued that if there are shared experiences within the organization, there can also be a total organizational culture. Nevertheless, there is the tendency for subunits within a complex organizational structure to have cultures that are independent and even in conflict with each other. Schein (1996) further argued that culture is a dynamic, powerful and stable phenomenon operating in organizations. It is asserted that culture influences an organization's financial performance (Rowden, 2002), internal development (O'Reilly, 1989), and strategic success (Hambrick, 1980; Harrigan, 1980; Shrader et al. 1984; Weidenbaum, 1979). Given the arguments encapsulating the definition of culture, it is critical to analyze the dynamics and constructs that formulate the core concepts of culture within the framework of an organization through the reflective lenses of Howard (1998) and Schein (1990).

\subsection{Leadership, Organizational Culture and Performance Framework}

A number of studies have also been conducted on the relationship between organizational culture and performance in both the public and private sector organizations. Three of such researches are summarized below. First, Cameron \& Quinn (2006) hypothesized that an institution with strong, congruent cultures shows significant strength over those with weaker cultures and sub-cultures. However, his study did not corroborate this hypothesis (Brown, 2007; Sckerl, 2002). Rather, his study showed that dominant culture types and not cultural strength was the real predictor of organizational performance (Cameron \& Quinn 2006). Further examination of his initial research findings revealed that the data also showed that each of the four cultural elements had a particular characteristic that was consistent with their model (Brown, 2007; Cameron \& Quinn 2006). Second, Kotter and Heskett (1992) conducted several research studies to examine the link between organizational culture and economic performance in government organizations. The researcher implemented a combined quantitative and qualitative case study to test the hypothesis on the relationship between organizational culture and long term performance. In summarizing their findings, Kotter and Heskett (1992) were able to identify with similar trends presented in Cameron's (2006) previous research. Four conclusions were drawn from this study: First, it was interesting to note that an organizational culture is more important that its subcultures. Second, an organizational performance is facilitated by a well-entrenched culture (Kotter \& Heskett, 1992). Third, organizational performance is greatly enhanced when it is adaptable and focuses on strategies that facilitate organizational, customers' and employees' needs. Finally, Kotter and Heskett (1992) found that adaptive culture has three major elements- shared vision and strength; a common understanding of the mission, goals and objectives; mutual support and trust.

Studies conducted in both laboratory and field settings have yielded consistent support for the performance-enhancing effects of transformational leadership in public and private organizations. Further, the transformational leader tends to focus more on a positive organization climate that supports professionalism and excellence which retards the perception of organizational politics (Bass \& Avolio, 1993; Lowe, Kroeck, \& Sivasubramaniam, 1996). Collectively, these studies support the arguments that transformational leaders, compared to other leaders or managers, tend to have more success for themselves and their organizations. Bass (1985), pointed out that a prevailing body of literature has represented the fact that there are positive correlations between transformational leadership styles and organizational performance. Yukl (2002) pointed out that many distinct conceptualizations are often lumped together under the umbrella of leadership performance including outcomes such as leader effectiveness, leader advancement, and leader emergence. Howard (1998) stated however, that the leader performance phenomenon is best measured by variables such as career success of the individual leader and performance of the group or organization. While each of these measures can be considered conceptually distinct, one must conclude, therefore, that each has different outcomes and their inclusion should depend on the objectives of the leadership performance phenomenon (Yukl, 2002). Based on the above assessment, the first hypothesis is suggested:

H1: Transformational leadership traits are positively related to organizational performance as defined by the Competing Values Framework.

H2: Transformational leadership traits are negatively related to organizational performance as defined by the Competing Values Framework

The relationship between organizational culture and the perception of organizational leadership in the private sector is expected to be different from the relationship between culture and leadership in the public sector. The organizational culture existing in the public sector is heavily shape by the perception of managerial politics due to political mandates and campaign promises. The managerial strategies dictating the cultural environment in the private sector are more aligned with vision, mission, power, role achievement and support. Organizational Culture will be positively associated with performance both in the public and private sector organizations.

A number of studies have also been conducted on the relationship between organizational culture and performance in both the public and private sector organizations. Three of such researches are summarized below. First, Cameron \& Quinn 
(2006) hypothesized that an institution with strong, congruent cultures shows significant strength over those with weaker cultures and sub-cultures. However, his study did not corroborate this hypothesis (Brown, 2007; Sckerl, 2002). Rather, his study showed that dominant culture types and not cultural strength was the real predictor of organizational performance (Cameron \& Quinn 2006). Further examination of his initial research findings revealed that the data also showed that each of the four cultural elements had a particular characteristic that was consistent with their model (Brown, 2007; Cameron \& Quinn, 2006). Second, Kotter and Heskett (1992) conducted several research studies to examine the link between organizational culture and economic performance in government organizations. The researcher implemented a combined quantitative and qualitative case study to test the hypothesis on the relationship between organizational culture and long term performance. In summarizing their findings, Kotter and Heskett (1992) were able to identify with similar trends presented in Cameron \& Quinn's (2006) previous research. the conclusions were drawn from this study: First, it was interesting to note that an organizational culture is more important that its subcultures. Second, an organizational performance is facilitated by a well-entrenched culture (Kotter \& Heskett, 1992). Third, organizational performance is greatly enhanced when it is adaptable and focuses on strategies that facilitate organizational, customers' and employees' needs. Finally, Kotter and Heskett (1992) found that adaptive culture has three major elements- shared vision and strength; a common understanding of the mission, goals and objectives; mutual support and trust. Finally, Denison (1990) conducted a series of studies using quantitative and qualitative methods to examine the continued impact of organizational culture on organizational performance. Thirty (30) supervisors from two (2) government organizations were surveyed. In the continued evaluation of Denison's (1990) performance theory, the four hypotheses were subjected to further research by Denison and Mishra (1995) and ultimately incorporated into the Denison's Culture and Performance Model (Denison, 1995. As a result, the second hypothesis is suggested:

H3: The perception of organizational Culture is positively related to organizational performance as defined by the Competing Values Framework.

H4: The perception of organizational culture is negatively related to organizational performance.

In addition, the direct relationship between leadership and organizational culture has not been investigated sufficiently. One of the most significant contributions of the model being proposed is its examination of the impact of the transformational leadership on organizational culture. In fact, Yukl (1994) argued that transformational leadership and organizational culture have become increasingly important over the last decade resulting in more than 5,000 studies on leadership. Further, the phenomenon of leadership and culture continues to draw interest of academics and practitioners in many fields, including sport management, public sector organizations and the health care industry. Block (2003) produced a seminal research on organizational leadership culture connection, and argued that the leadership and culture are so central to understanding organizations and making them effective that students of organizational behavior cannot afford to be complacent about either one. Additionally, it was argued that current models of organizational performance and change suggest that leadership and organizational culture are central explanatory constructs (Ogbonna \& Harris, 2000; Schein, 1992). Blackwell (2006) noted the importance of culture and leadership by arguing that organizational culture influences organizational behavior, and helps frame and shape the use of leader behavior. Bass and Avolio (1991), on the other hand, asserted that a purely transformational culture is conceptualized as having a close net relationship with organizational members. In this relationship, commitments are long-term; individuals share mutual interests; and there is a sense of shared fates and interdependence across divisions and departments. H5: The perception of organizational performance mediates the relationship between transformational leadership and organizational culture as defined by the Competing Values Framework.

This paper used a combination model of the Bass and Avolio (1991) MLQ Form 5X- short form, and the Organizational Culture Assessment Instrument (OCAI) developed by Cameron and Quinn (2006) which seek to understand the relationship between the key factors of leadership traits and culture types by organizational decision-makers and whether these decisions are randomly or strategically made. Individual factors impacting organizational decisions are analyzed, and different types of organizational culture types are investigated. Consequently, the objective is to make suggestions on the use of best practices that management can implement in organizational setting. In summary, the research seeks to answer three direct questions:

1. What are the impact of the relationship between leadership traits and culture types on organizational performance?

2. How can the practice of the four culture types and their interaction with the five leadership traits contribute to organizational effectiveness?

3. How can these relationships, if any exist, contribute to the understanding organizational productivity and efficiency by decisions makers? 


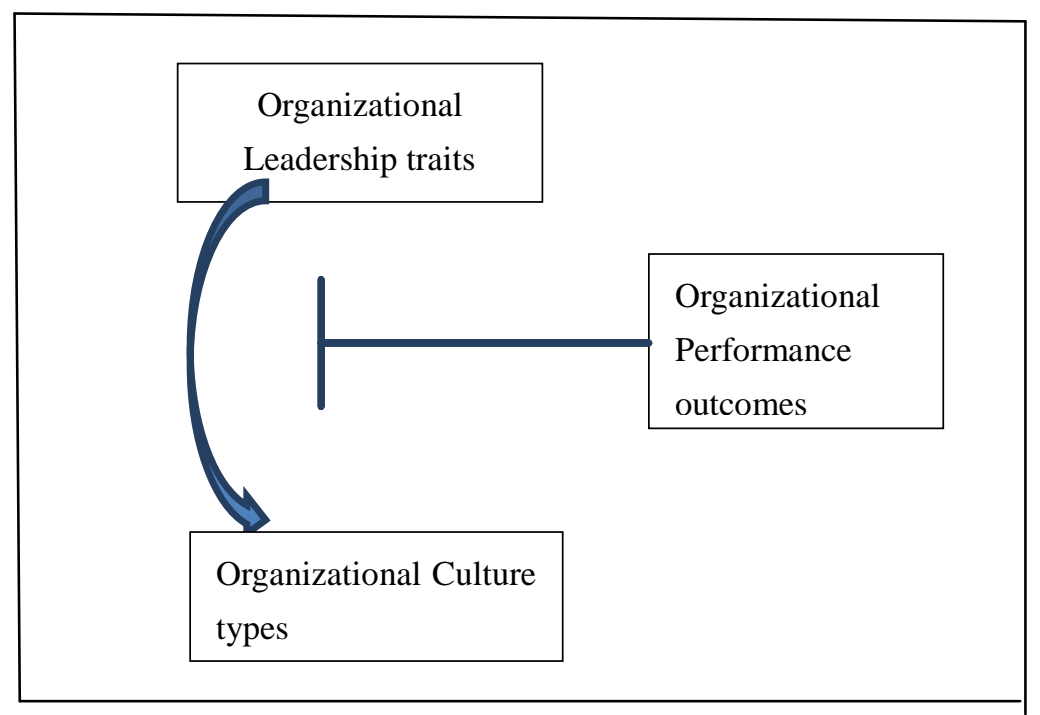

Figure 1. Research framework of leadership culture and performance (based on the Flemming, 2009) Model)

\section{Methodology}

This research implemented survey design and the analysis was based on primary data collected from respondents (Creswell, 2003; Yin, 2003). The research methodology seeks to verify the coexisting factors between leadership style and organizational culture types. The survey instrument of choice that was used to determine the leadership style is the MLQ Form 5X-short form developed by Bass and Avolio (1994), and Bass (1985) in their study Transformational Leadership and performance which is considered to be a widely used instrument in measuring leadership styles in public sector organizations. The variables tested were Idealized Influence Behavior, Inspirational Motivation, Intellectual Stimulation, Individualized Consideration, Idealized Influence. The survey design also was modified to includes the Organizational Culture Assessment Instrument (OCAI) developed by Cameron and Quinn (2006). The independent variables are the transformational and transactional leadership traits. The dependent variables were classified as organizational culture outcomes: Clan Culture Adhocracy Culture, Market Culture, and Hierarchal Culture types supporting the perception organization power orientation, role orientation, achievement orientation, and support orientation in the selected public sector organizations. The questions embedded in the questionnaire were related to leadership traits and performance as measure by effectiveness and satisfaction and organizational culture types which are variables proposed by Cameron and Quinn (2006). This study implemented these variables to analyze the relationship between leadership traits, culture types and performance of public and private sector organizations in the sample area. In the MLQ Form 5X-short form, each independent variable were given equal weighting with an options to answer five statement with five potential responses in the form of a likers scale ranging from 0 to 4 with " 0 " denoting not at all to a " 4 " all the time (Obiwuru, Okwu, Akpa, Nwankwere, 2011). The OCAI had a range of 1 to 4 with a " 1 " that least describes the way things are in your organization to a "4" that describes the way things are in your organization.

\subsection{Sample and Procedure}

The target population for this survey comprised of employees working-full time in various private and government organizations or agencies in the Virgin Islands. One reason for selecting this sample population is based in part of a recent study of leadership in the Caribbean. Mills (2007) argued that there is a need for further research into public and private sector leadership in evaluating organizational performance in the United States Virgin Islands given the overwhelming dissatisfaction from the general public with government managed entities. The aim then was to examine sampling of workers comprised of employees currently working in government organizations established by the Virgin Islands Code.

Twenty (20) surveys were distributed to ten organizations creating a total sample size of 200. The goal of this survey was to obtain a return of $20 \%$ to $30 \%$ responses. Five public sectors and five private sectors organizations were selected through a stratified random sample technique to make up a total sample size of 10 organizations. Twenty respondents were administered questionnaires from each of the 10 organizations. Copies of the questionnaires were distributed to participants in the survey with instructions on how to complete them. From the 20 survey forms that were distributed all were returned completely filled out according to the instructions given a return rate of $100 \%$. The high return was due to the fact that the questionnaires were administered in a workshop setting where the researcher was present and provide clear instructions regarding the purpose of the research. The survey forms were filled out voluntarily and willingly after 
the explanation and rational was given in support of the study. All three sections: leadership, organizational culture and performance were filled out by individuals assigned to each organization mainly for distribution and collection purposes. Permission was requested to use this survey instrument from Cameron and Quinn (2006) and Bass and Avolio (1994). The data analysis used was SPSS Statistical Software package. Correlation and ordinary least squares (OLS) multiple regression analysis models (Obiwuru T., et. al. 2011) were used to analyzed the relationships between the leadership style, performance and organizational culture types.

\subsection{Measurement}

This study utilized a survey instrument in the form of a Multifactor Leadership Questionnaire (MLQ) Form 5X to collect data on leadership behavior, and organizational performance, and the Organizational Culture Assessment Instrument (OCAI) developed by Cameron and Quinn (2006) was used to measure organizational culture types. A review of the literature revealed that there are several instruments designed to assess transformational leadership, and the best-known and most rigorously assessed instrument is the Multifactor Leadership Questionnaire (MLQ) Form 5X (Javidan \& Waldman, 2003). Originally designed by Bass (1985), and updated by Bass and Avolio (1990), the MLQ is psychometrically tested for reliability and validity. The MLQ Form 5X by Bass and Avolio (1990), is a self-reporting questionnaire consisting of 45 questions regarding leaders' behaviors. Bass and Avolio (1990) stated that form 5X consist of five sub-scales consisting of four items each assessed the characteristics of transformational leadership to include idealized influenced behavior, inspirational motivation, intellectual stimulation, and individual consideration. Form 5X also contains three sub-scales of four items measuring the transactional leadership component of contingent rewards, active management by exception, and passive management by exception (Avolio \& Howell \& Sosick, 1992; Bass, 1985; Hater \& Bass, 1988; Bass, 1999; Schimmoeller, 2006). Bass and Avolio (1990) further noted that the MLQ Form 5X measures specific leaders' behavior by using a 5- point Likert Scale. This statement was corroborated by (Howell \& Avolio, 1993; Sekaran, 2003) who stated that the 5-point Likert Scale responses ranging from "not at all" to "frequently if not always". The 5- point scale approach was incorporated into the research instrument to be used in this study (Avolio \& Bass, 1994). Three sub-scales of five items also measuring hiring decisions, performance measurement, job satisfaction and reward system reflective of organizational performance.

\subsection{Analysis of Data}

This study utilized descriptive statistical analysis to corroborate the data. A combination of two statistical packages were implemented, namely, SPSS Statistical Software package 14.0 and Microsoft Excel Software package to transform primary data into information that is understandable. In order to fully represent the data analysis, the information was summarized, categorized, and calculated using the mean, median and the mode methods (Cooper \& Schindler, 2006). The standard deviation and the percentage of distribution were factored into the analysis in order to accomplish the analytical task (Creswell, 2003). The data were also analyzed using the chi-square tests of significance to evaluate the difference between the observed frequency and the frequency of nominal data (Cooper \& Schindler, 2006; Pendhazur, 1982). Emphasis was also placed on testing cross-tabulation of nominal data between selected variables. The statistical significance difference targeted was $\mathrm{p}<.05$. alpha levels which is typical in most research (Cooper \& Schindler, 2006; Pendhazur, 1982).

\section{Results}

The data was analyzed in three stages: Demographics, Factor analysis, and Regression Analysis. First, the data was examined using descriptive statistics to understand the samples without testing the hypotheses. The age of the respondents ranges from 22 to 55 . The mean age was 42.3 years with a standard deviation of 11.72 . Gender was $34 \%$ male and $65 \%$ female. $98 \%$ of the respondents reported full-time tenure with their organizations with a mean of 9 years. 5\% of the respondents reported tenure with less than 5 years, while 3\% reported tenure with less than 1 year. Although the demographics were incorporated into the data set, they were only used to better understand the sample, and were not used in the analysis of the questionnaires. The results of the sample showed that the respondents were mostly females, well-experienced and have a long tenure with their organizations (Flemming, 2009).

Table 1. Market Culture Leadership Performance Traits Regression

\begin{tabular}{lccccc}
\hline & $\mathrm{R}$ & $\mathrm{R}$ Square & Adj. R Square & $\mathrm{t}$ & sig. \\
\hline Organizational performance & $\mathbf{. 1 0 8}$ & .012 & .006 & $\mathbf{1 . 4 8 7}$ & .139 \\
Idealized Influence Behaviour & $\mathbf{. 1 1 6}$ & .014 & .003 & $\mathbf{- . 6 0 8}$ & .544 \\
Inspirational Motivation & $\mathbf{. 2 3 9}$ & .057 & .042 & $\mathbf{2 . 9 4 1}$ & $.004 *$ \\
Intellectual Stimulation & $\mathbf{3 0 8}$ & .095 & .075 & $\mathbf{2 . 7 7 4}$ & $.006 *$ \\
Idealized Influence Attributes & $\mathbf{. 3 0 9}$ & .096 & .071 & $\mathbf{- . 4 5 6}$ & .649 \\
Individualized Consideration & $\mathbf{. 1 0 7}$ & .012 & .006 & $\mathbf{1 . 4 8 6}$ & .139 \\
\hline
\end{tabular}

As shown in Table 1, transformational leadership traits are dependent on market organizational culture type as defined by the Competing Value Framework and depicted by the significant (sig) value of .05. The sig. value varies between.004* 
level, and .554 level which indicates that there is significant low difference between the relationship of transformational leadership traits and market culture types at $\mathrm{r}=.108 ; .116 ; .239 ; .308 ; .309$, and .107 ; but at $\mathrm{p}=1.487 ;-.608 ; 2.941 ; 2.774$; -.456 , and 1.486 respectively are significant to the 0.05 level of significance. Therefore, the null hypothesis (Ho) is rejected. The regression analysis calculates the adjusted $\mathrm{r}$ squared values low at $.006 ; .003 ; .042 ; .075$, and .006 respectively which are consistent with the findings of Avolio \& Bass (1995); Bass and Avolio (1994); Cameron and Quinn (2006) who argued that leadership traits are evident in market organizational culture. This study identified the leadership type as transformational leadership as illustrated in Table 1. Therefore, H2: Transformational leadership traits are positively related to organizational performance as defined by the Competing Values Framework was validated.

Table 2. Pearson Test of Correlation of Organizational Culture types with Performance

\begin{tabular}{lllll}
\hline & Clan & Adhocracy & Market & Hierarchal \\
\hline Clan Correlation & 1.000 & -0.315 & -0.315 & -0.265 \\
Sig (2-tailed) & -0.315 & 0.000 & 0.000 & 0.000 \\
Adhocracy Correlation & 0.000 & -000 & 0.194 & -0.543 \\
Sig (2-tailed) & -0.315 & 0.194 & 0.008 & 0.000 \\
Market Correlation & 0.000 & 0.008 & 1.000 & -0.484 \\
Sig (2-tailed) & -0.265 & -0.543 & - & 0.000 \\
Hierarchal Correlation & 0.000 & 0.000 & -0.484 & 1.000 \\
Sig (2-tailed) & & 0.000 &. \\
\hline
\end{tabular}

As shown in Table 2, the correlation between culture types and organizational performance. As depicted in Table 2, when the sig. value (p-value) was compared to the significant level .05 the analysis showed that the $\mathrm{p}$-value was less than .05 which indicates that there is a correlation between organizational performance and culture types. The correlation coefficient was weak at -0.315 ; $-0.265 ;-0.543 ;-0.484$, but strong at $1.00 ; 0.194$. This finding was consistent with Cameron and Quinn, (2006) who asserted that the existence of a strong hierarchal and clan culture in public sector organizations facilitates increased performance. This study also found a strong existence of adhocracy and market culture in public sector organizations. These findings are best explained by the approaches that government is now taking to promote their services and to collaborate in joint venture projects which are more evident in private sector organizations. A factor analysis was also conducted in this study using the components of transformational leadership traits and culture types yielding a cumulative percentage of 97.365 for the Kaiser-Meyer-Olkin Measure of Sampling adequacy and a significant Bartlett's Test of Sphericity. As depicted in Table 5, the total variance explained by the factors of Clan, Adhocracy, and Market Culture are 50. 3\%; 20. 5\% and 12. $0 \%$ with only three components extracted. Reliability reported in this scale is .96 which further supports the theory that the components of transformational leadership and culture types are not independent of each other in this study (Flemming, 2009).

An aggregated variance analysis was also conducted on transformational leadership traits and organizational culture to identify those items that were appropriately correlated to organizational culture types using variance procedures. First, the mean score for each of the six transformational leadership scales was calculated, then a comparison of the means was conducted for each item to evaluate the appropriateness of each score (i.e. statistically significantly higher on the appropriate definition utilizing t-tests; $p<$ 0.05). The analysis indicated that the sample size was adequate for assessing the practical significant differences between the means. The analysis also indicated that the mean scores of Organizational Performance (Org. PF.) = 37. 50; Idealized Influence Behavior $(\mathrm{IIB})=37.50$; and Inspirational Motivation $(\mathrm{IM})=43.75$; are significant when compared to Hierarchal Culture types Intellectual Stimulation (IS); Individualized Consideration (IC) and Idealized Influence Attributes (IIA), reported less significant with 29.88; 30.42; and 29.17 respectively. Thus: H3: The perception of organizational Culture is positively related to organizational performance as defined by the Competing Values Framework was validated.

Table 3. Correlation of Transformational Leadership Traits and Culture types

\begin{tabular}{|c|c|c|c|c|}
\hline & Clan & Adhocracy & Market & Hierarchal \\
\hline \multicolumn{5}{|l|}{ Idealized Influence Behaviour } \\
\hline Correlation coefficient & $3.333 *$ & $-0.367 *$ & -0.257 & 0.268 \\
\hline $\mathrm{p}$-value & $0.000 *$ & $0.022 *$ & 0.142 & 0.114 \\
\hline \multicolumn{5}{|l|}{ Inspirational Motivation } \\
\hline Correlation coefficient & $-0.362 *$ & $0.339^{*}$ & $0.322 *$ & $-0.328 *$ \\
\hline $\mathrm{p}$-value & $0.002 *$ & $0.001 *$ & $0.005^{*}$ & $0.003 *$ \\
\hline \multicolumn{5}{|l|}{ Intellectual Stimulation } \\
\hline Correlation coefficient & -0.226 & $-0.419 *$ & $0.447 *$ & $-0.358 *$ \\
\hline p-value & 0.176 & $0.006^{*}$ & $0.008^{*}$ & $0.028 *$ \\
\hline \multicolumn{5}{|l|}{ Individualized Consideration } \\
\hline Correlation coefficient & $0.476^{*}$ & $-0.459 *$ & -0.169 & 0.232 \\
\hline p-value & $0.001 *$ & $0.001 *$ & 0.241 & 0.096 \\
\hline \multicolumn{5}{|l|}{ Idealized Influence Attributes } \\
\hline Correlation coefficient & -0.196 & $-0.538^{*}$ & -0.078 & $0.530 *$ \\
\hline p-value & 0.160 & $0.000^{*}$ & 0.579 & $0.000 *$ \\
\hline
\end{tabular}


Note. *Highlighted values are significant at p-values that are less than .05

As exhibited in Table 3, it is important to note that this investigation found strong correlations with transformational leadership traits and organizational culture types in public and private sector organizations. Flemming (2009), pointed out that the links are positively related with Clan 3.333; Adhocracy 0.459, .538; and Hierarchal culture .268, .232 respectively. What was surprising, however, is the positive link between Market culture .322, and .447, and transformational leadership traits in public sector organizations which Cameron and Quinn (2006) asserted is more prominent in private sector organizations. It should be noted that the links are related significantly at the stated .05 level of significance, and the p-values are also significant between the correlations coefficients. Thus H5: The perception of organizational performance mediates the relationship between transformational leadership and organizational culture as defined by the Competing Values Framework was also validated. The implications of these findings from the standpoint of management, and their impact on organizational performance will be discussed further (Flemming, 2009).

Table 4. Summary of Leadership, performance and Culture Regression

\begin{tabular}{llllll}
\hline & $\mathrm{R}$ & $\mathrm{R}$ Square & Adj. R Square & $\mathrm{t}$ & sig \\
\hline Organizational Effectiveness & .320 & .102 & .073 & 11.793 & .159 \\
Idealized Influence Attributes & .383 & .147 & .124 & 3.771 & $.000^{* *}$ \\
Individualized Consideration & .306 & .094 & .089 & -4.425 & $.000^{* *}$ \\
Inspirational Motivation & .197 & .039 & .023 & -2.650 & $.009^{* *}$ \\
Intellectual Stimulation & .308 & .95 & .075 & 2.774 & $.006^{*}$ \\
Idealized Influence Behaviour & .335 & .112 & .103 & -4.803 & $.000^{* *}$ \\
\hline
\end{tabular}

As depicted in Table 4, the sig. value p-value is less than .05 which enforced the fact that transformational leadership traits depend on organizational culture types in public and private sector organizations. The analysis further showed that transformational leaders possess a variety of culture characteristics which support the findings of Bass and Avolio (1994); Avolio and Bass (1995); and Cameron and Quinn (2006), who argued that transformational leaders appeal to their followers in different ways. There was also sufficient evidence to conclude that organizational performance or effectiveness depends on organizational culture types with a p -value of .159.

\section{Discussion and Proposed Framework}

There were five critical dimensions that were imbedded in the questionnaires. The first dimension was represented by four Idealized Influence Behavior (IIB) and four Idealized Influence Attributes items. These items were primarily associated with a leader's ability to behave in ways that reflect strong ethics, possesses strong role-model principles, is admired, respected and trusted (Bass \& Avolio, 1994; Avolio \& Bass, 1995). A second dimension included four Intellectual Stimulation items suggesting that transformational leaders stimulate their followers' efforts to be innovative and creative by questioning assumptions; reframing problems; developing new and innovative ways to resolve old problems (Bass $\&$ Avolio, 1994; Avolio \& Bass, 1995). The third dimension was represented by four Inspirational Motivation items suggesting that transformational leaders behave in ways that motivate and inspire their followers by providing meaning and challenge to their followers' work (Bass \& Avolio, 1994; Avolio \& Bass, 1995). The fourth dimension evaluated the ability of transformational leaders to address the needs of their followers for achievement and growth by acting as coach or mentor (Bass \& Avolio, 1994). The final dimension consisted of four items that measure the ability of transformational leaders to effectively represent their followers by enhancing their ability to achieve organization's goals and objectives. This research has found transformational leadership to be positively correlated with the leader's satisfaction, effectiveness of the leader, role clarity, mission clarity, and openness of communication (Pendhazur (1982); Hinkin \& Tracey, 1999). The study described transformational leadership as influencing major changes in public sector, organizations' members and building commitment for the organizational objectives. Consistent with the findings of Timothy et al. This study should lead us to question whether or not more emphases should be placed on evaluating the mindset of political employees when they are appointed to leadership roles in public organizations. Finally, this study found organizational performance to be positively correlated with transformational leadership traits and organizational culture types which is consistent with the research conducted by Hinkin and Tracey (1994), that also found transformational leadership to be positively correlated with satisfaction and leader's effectiveness/performance. Further research is also required to investigate a wider sampling frame and to examine the relationship between leadership and culture behaviors and relevant organizational outcomes. This study hypothesized and proved that the relationship between transformational leadership traits and organizational culture types is critical in order to achieve organizational performance. Although this study confirmed that transformational leaders possess the ability to effectively enhance organizational performance, this research did not examine the correlation of other leadership styles such as transactional, and Laissez-Faire with different organizational culture types. Further study is recommended using other leadership styles so that leaders can fully understand and appreciate the appropriate methodology that will effectively enhance performance in specific public sector organizations. 


\subsection{Research Limitation}

It is important to point out the limitations associated with this study. First, there is no one ideal model that can be used to resolve all problems related to the leadership and culture phenomenon that exist in public sector organizations. Therefore, any design and restructuring of an existing organization must consider the ramifications associated with the external and internal environments, and the vested interest of the stakeholders before implementing any findings based on this research. Secondly, the research implemented the MLQ rater form for participants to rate their leaders, and did not include the leader form for leaders to rate their own leadership behavior.

\subsection{Research Implications}

There are several important managerial and leadership implications derived from this research for public sector organizations. The major implications that can add to the body of knowledge will be highlighted in this section. First, this study supported the empirical research by Cameron and Quinn (2006) who asserted that hierarchy culture is present in large organizations and government agencies, as evident by standardized procedures, multiple hierarchical levels and an emphasis on rule enforcement. However, this study adds to the body of knowledge by discovering that transformational leadership traits are strongly embedded in Hierarchy, Clan, Adhocracy and Market cultures, hence supporting the assumption that these leaders exhibit visionary and inspirational behaviors. This finding also supports Avolio and Bass (1995); and Bass and Avolio (1994) research that successfully argued the case that transformational leaders are effective change agents and followers are more motivated to perform by an inspiring vision from transformational, charismatic leaders than by just the premise of rewards based on performance. Second, from a practical standpoint, it is useful for leaders in public and private sector organizations to understand the positive correlation between organizational leadership and the organizational culture. The understanding of this framework, as discovered by this study, can greatly enhance organizational performance by articulating a clear and aggressive strategy which ultimately will lead to productivity and efficiency. The implementations of these findings will also enable leaders to communicate on where the organizations are going; develop the skills and abilities of subordinates; and encourage innovative problem-solving. Similarly, with this model framework, leaders can conceptualize that it is these leadership behaviors that can truly transform organizations from a static environment to a more efficient and effective workplace.

\section{Concluding Remark}

This study found organizational performance to be positively correlated with transformational leadership, Hierarchy and Clan cultures which are consistent with the research conducted by Hinkin and Tracey (1999), that also found transformational leadership to be positively correlated with satisfaction and leader's effectiveness. There was also sufficient evidence to conclude that leaders should seek to understand their organizational culture to achieve strategic performance. Future research should involve a closer examination of the correlation between organizational performance and transformational leadership traits in public and private organizational using a wider sampling frame. Further research is also required to examine the relationship between leadership and culture behaviors and relevant organizational outcomes.

\section{Acknowledgements}

The author would like to thank Dr. Barbara Flemming for her insights, critical review and feedback on the research data and to acknowledge her continued encouragement that enables me to write this research paper. Additionally, the author is grateful for the assistance of the Commissioners, Directors and Supervisors throughout the governmental agencies and corporate organizations for allowing their employees to participate in the survey; and also for their honest feedback in sharing their opinions and issues in relation to culture, leadership, and performance. The author is solely responsible for any inconsistencies and errors in analyzing the data that may be evident in this paper.

\section{References}

Avolio, B. J., Bass, B. M., \& Jung, D. I. (1999). Re-examining the components of transformational and transactional leadership using the multifactor leadership questionnaire. Journal of Occupational \& Organizational Psychology, 72, 441-462. http://dx.doi.org/10.1348/096317999166789

Avolio, B. J., Howell, J. M., \& Sosik, J. J. (1999). A funny thing happened on the bottom line: humor as a moderator of leadership style effects. Academy of Management Journal, 42, 219-227. http://dx.doi.org/10.2307/257094

Banerij, P., \& Krishnan, V. R. (2000). Ethical preferences of transformational leaders: An empirical investigation. Leadership \& Organizational Development Journal, 21(8), 1-11. http://dx.doi.org/10.1108/01437730010358161

Barbuto, J. E. (2005). Motivation and transformational, charismatic, and transformational leadership: A Test of Antecedents. Journal of Leadership \& Organizational Studies, 11(4), 1-13.

http://dx.doi.org/10.1177/107179190501100403 
Bass, B. M. (1985). Leadership and performance beyond expectations. New York: Free Press.

Bass, B. M. (1999). Two decades of research and development in transformational leadership. European Journal of Work and Organizational Psychology, 8(1), 9-32. http://dx.doi.org/10.1080/135943299398410

Bass, B. M., \& Avolio B. J. (1994). Improving organizational effectiveness through Transformational leadership.

Bass, B. M., \& Avolio, B. J. (Spring, 1993), Transformational leadership and organizational culture: Public Administration Quarterly, 17(1), 112-121.

Bass, B. M., \& Avolio, B. J. (1991). The multifactor leadership questionnaires Form 5X. Center for Leadership Studies, State University of New York. Binghamton, NY.

Blackwell, S. S. (2006). The influence of perceptions of organizational structure \& culture on leadership role requirements: The moderating impact of locus of control \& self-monitoring. Journal of Leadership \& Organizational Studies, 12(4), 1-27.

Block, L. (2003). The relationship between transformational leadership styles and organizational culture connection in improving performance in public sector. The leadership-culture connection: An exploratory investigation. Leadership \& Organization Development Journal, 24(5/6), 318-334. http://dx.doi.org/10.1108/01437730310494293

Brown, E. M. (2007). An examination of the link between organizational culture and performance: A study of three county public health departments (Doctoral dissertation, University of California, Berkeley, 2007). UMI Publication No. AAT 3306035.

Burns, J. M. (1978). Leadership. Harper \& Row, New York, N.Y.

Cameron K, S., \& Quinn, R. E. (2006). Diagnosing and changing organizational culture. (Revised Edition). San

Carless S. A. (1998). Assessing the discriminant validity of transformational leader behavior as measured by the MLQ. Journal of Occupational and Organizational Psychology, 4(71), 353-358.

http://dx.doi.org/10.1111/j.2044-8325.1998.tb00681.x

Casimir, G., Waldman, D. A., Bartram, T., \& Yang, S. (2006). Trust and the relationship between leadership and follower performance: Opening the Box in Australia and China. Journal of Leadership \& Organizational Studies, 12(3), 1-14. http://dx.doi.org/10.1177/107179190601200305

Cooper, D. R., \& Schindler, P. S. (2006). Business research methods. ( $9^{\text {th }}$ Eds.). New York: McGraw-Hill.

Creswell, J. W. (2003). Research design: Qualitative, quantitative, and mixed methods approach. Thousand Oaks: Sage Publication.

Denison, D. R. (1990), Corporate Culture and Organizational Effectiveness, New York: Wiley.

Denison, D. R., \& Mishra, A. K. (1995). Towards a theory of organizational culture and effectiveness. Organization Science, 6(7) 204-222. http://dx.doi.org/10.1287/orsc.6.2.204

DeTienne, K. B., Dyer, G., Hoopes, C., \& Harris, S. (2004). Toward a model of effective knowledge management and directions for future research: Culture, leadership, and CKOs. Journal of Leadership \& Organizational Studies, 10(4), 26-43. http://dx.doi.org/10.1177/107179190401000403

Farkas, C. M., \& Wetlaufer, S. (1996). The way chief executive officer leads. Harvard Business Review, 74(3), 1-16.

Felfe, J., \& Schyns, B. (2004). Is similarity in leadership related to organizational outcomes? The case of transformational leadership. Journal of Leadership \& Organizational Studies, 10(4), 92-102. http://dx.doi.org/10.1177/107179190401000407

Flemming, P. L. (2009). A study of the relationship between transformational leadership traits and organizational culture types in improving performance in public sector organizations: A Caribbean Perspective. Doctoral dissertation, Capella University. UMI Publication No. 3366452. Francisco: The Jossey-Bass.

Gardner, J. W. (1990). On leadership. New York, New York: Free Press.

Gordon, G. J., \& Milakovich, M. E. (1998). Public administration in America. (6 $6^{\text {th }}$ Eds.). New York, N.Y: St. Martin's Press.

Guth, W. D. (1980). Corporate growth strategies. Business policy and strategic management. The Journal of Business Strategy, 85(3), 1-16. http://dx.doi.org/10.1108/eb038899

Hambrick, D. C. (1980). Operationalizing the concept of business-level strategy in research. Academy of Management Review, 5(4), 567-576. 
Harrigan, K. R. (1980). Strategy formulation in declining industries. Academy of Management Review, 5(4), $599-604$.

Hater, J. J., \& Bass, B. M. (1988). Superiors' evaluation and subordinates' perceptions of transformational and transactional leadership. Journal of Applied Psychology, 73, 695-702. http://dx.doi.org/10.1037/0021-9010.73.4.695

Hendrick, R. (2003). Strategic planning, environment, process, and performance in public agencies. Journal of Public Administration Research and Theory, 13(4), 491-519. http://dx.doi.org/10.1093/jopart/mug031

Hersey, P., \& Blanchard, K. H. (1988). Management of organizational behavior: Utilizing human resources. $\left(5^{\text {th }}\right.$ Eds.). Upper Saddle River, N. J.: Pearson Prentice Hall.

Higgs, M. (2003). How can we make sense of leadership in the 21st century? Leadership \& Organization Development Journal, 24(5/6), 273-284. http://dx.doi.org/10.1108/01437730310485798

Hinkin, T., \& Tracey, J. (1999). The relevance of charisma for transformational leadership in stable organizations. Journal of Organizational Change Management, 12(2), 105. http://dx.doi.org/10.1108/09534819910263659

Hooijberg, R., \& Petrock, F. (1993). On cultural change: Using the competing value framework to help leaders execute a transformational strategy. Human Resource Management, 32(1), 1-29. http://dx.doi.org/10.1002/hrm.3930320103

Howard, L. (1998, July). Validating the competing values model as a representation of organizational cultures. International Journal of Organizational Analysis (1993 - 2002), 6(3), 231.

Javidan, M., \& Waldman, D. (2003, March). Exploring Charismatic Leadership in the Public Sector: Measurement and Consequences. Public Administration Review, 63(2), 229-242. http://dx.doi.org/10.1111/1540-6210.00282

Kotter, J. P., \& Heskett, J. L. (1992). Corporate Culture and Performance. New York, NY: The Free Press.

Llies, R., Judge, T., \& Wagner, D. (2006). Making sense of motivational leadership: The trail from transformational leaders to motivated followers. Journal of Leadership \& Organizational Studies, 13(1), 1-22. http://dx.doi.org/10.1177/10717919070130010301

Lowe, K. B., Koreck, K. G., \& Sivasubramaniam, N. (1996). Effectiveness correlates of transformational and transactional leadership: A meta-analytic review of the MLQ Literature. Leadership Quarterly, 7(3), 385-425. http://dx.doi.org/10.1016/S1048-9843(96)90027-2

Mahgoubali, T. E. (2004). The role of public sector leadership in fostering socio-economic and political development in Africa. United Nations Department of economic and Social Affairs, 1(1), 27-30.

Mills, F. (2007). Caribbean perspectives. A leadership research publication of the Eastern Caribbean Center, 2(6), 1-27.

Mumford, M., Zaccaro, S., Harding, F., Jacobs, T., \& Fleishman, E. (2000). Leadership skills for a changing world: Solving complex social problems. Leadership Quarterly, 11(1), 11. http://dx.doi.org/10.1016/S1048-9843(99)00041-7

Nahavandi, A. (2006). The art and science of leadership. (4 ${ }^{\text {th }}$ Ed.). Upper Saddle River, New Jersey: Pearson Prentice Hall.

Northouse, P. G. (2004). Leadership: Theory and practice. ( ${ }^{\text {rd }}$ Ed.). Thousand Oak, California: Sage Publication.

Ogbonna, E., \& Harris, L. C. (2000). Leadership style, organizational culture and performance: Empirical evidence from UK companies. International Journal of Human Resource Management, 11(1), 766-788. http://dx.doi.org/10.1080/09585190050075114

O'Reilly, C.A. (1989). Corporation, culture, and commitment: Motivation and social control in organizations. California Management Review, 31, 9-25. http://dx.doi.org/10.2307/41166580

Parry, W. K. (1999). Enhancing adaptability: leadership strategies to accommodate change in local government setting. Journal of Organizational Change Management, 12(2), 134-156. http://dx.doi.org/10.1108/09534819910263677

Parry, W. K. (2003). Leadership, culture and performance: The case of the New Zealand public sector. Journal of Organizational Change Management, 12(4), 376-399.

Pendhazur, E. J. (1982). Multiple regressions in business research. Holt, Rinehart, \& Winston, Fort Worth, TX.

Reynolds, P. D. (1986, May). Organizational culture as related to industry, position and performance: A preliminary report. Journal of Management Studies, 23(3), 333-345. http://dx.doi.org/10.1111/j.1467-6486.1986.tb00958.x

Robbins, C. (2002). Real world research ( $2^{\text {nd }}$ Ed.) USA: Blackwell Publishing. R. R.

Rowden, R. (2002). The strategic role of human resource management in developing a global corporate culture. International Journal of Management, 19(2), 155-160. 
Schein, E. (1990). Organizational culture and leadership. San Francisco: Jossey-Bass.

Schein, E. (1990). Organizational culture. American Psychologist, 45(2), 109-119. http://dx.doi.org/10.1037/0003-066X.45.2.109

Schein, E. H. (1992), Organizational Culture and Leadership. San Francisco: Jossey-Bass.

Schein, E. H. (1996). Culture: The missing concept in organizational studies. Administratively Science Quarterly, 41, 229-240. http://dx.doi.org/10.2307/2393715

Schimmoeller, L. J. (2006). An empirical investigation of the relationship between organizational culture and leadership styles. Unpublished doctoral dissertation. University of Toronto Canada, UMI 3244423.

Scholz, C. (1987). Corporate culture and strategy. The problem of strategic fit. Long Range Planning, 26(4), 79-85. http://dx.doi.org/10.1016/0024-6301(87)90158-0

Sckerl, J. M. L. (2002). Organizational culture in higher education effectiveness: A case study of a Midwest university in change. UMI Proquest Digital Dissertations, AAT 3048765.

Shrader, C. C., Taylor, L., \& Dalton, D. R. (1984). Strategic planning and organizational performance: A critical appraisal. Journal of Management, 10(2), 149-171. http://dx.doi.org/10.1177/014920638401000202

Starling, G. (1993). Managing the public sector. ( $4^{\text {th }}$ Ed.). Belmont, Ca: Wadsworth Publishing Company.

Thousand Oak: Sage Publication.

Weidenbaum, M. L. (1979). Public policy: No longer a spectator sport for business. (2nd Ed.) Englewood Cliffs, NJ: Prentice.

Yin, R. (2003). Case study research design and methods ( $3^{\text {rd }}$ Ed.). Thousand Oak: Sage Publication.

Yukl, G. (2002). Leadership in organizations. (5 ${ }^{\text {th }}$ Ed.). Upper Saddle River, NJ: Prentice Hall.

\section{(cc) EY}

This work is licensed under a Creative Commons Attribution 3.0 License. 